\title{
Problemática territorial y conservación de la biodiversidad en espacios protegidos de Argentina
}

\author{
Territorial Conflicts and Conservation of Biodiversity \\ in Protected Areas of Argentina
}

\author{
Juan Pablo Morea ${ }^{1}$
}

\section{Resumen}

La problemática territorial en América Latina se ha profundizado en los últimos años a consecuencia de un importante proceso de expansión de las actividades productivas del sector primario. Esta problemática, que tiene basamento en la relación disfuncional sociedad-naturaleza, en un contexto de economía globalizada ha adquirido nuevas formas y ha instaurado nuevas lógicas que han impulsado a una profundización de los desequilibrios territoriales. Desequilibrios que han generado una degradación del ambiente que se contrapone con la tendencia mundial de conservar la biodiversidad, y producen un conflicto de intereses entre la conservación y el desarrollo económico. Mediante un abordaje que combina una exhaustiva revisión bibliográfica con el estudio del caso argentino, en este trabajo se explora la problemática territorial en torno a los espacios protegidos caracterizando las nuevas lógicas del proceso expansionista y la conflictividad social asociada a estos procesos. Los resultados demuestran que el avance de las fronteras productivas es cada vez mayor, que los espacios protegidos y la biodiversidad se encuentran fuertemente amenazados y que las políticas en materia de conservacionismo no han logrado contrarrestar el fenómeno expansionista.

Palabras clave: Problemática territorial; Conservación de la biodiversidad; Espacios protegidos; Conflictividad social; Argentina.

\begin{abstract}
The territorial conflict in Latin America has deepened in recent years as a result of a significant expansion of the productive activities of the primary sector. This problem, in a globalised economy context, has acquired new forms and it has established new logic that has worsened territorial imbalances. This situation has resulted in a degradation of the environment, which is at odds with the global trend of biodiversity conservation, and it has produced a conflict of interests between conservation and economic development. Using an approach that combines a comprehensive literature review with the Argentinian case study, this paper explores the territorial problems affecting protected areas thus characterizing the new logic of the expansionist process and the social conflict associated with them. The results show that the productive borders are advancing, that protected areas and biodiversity are significantly threatened and that the conservation policies have failed to counteract the expansionist phenomenon.
\end{abstract}

Key Words: Territorial conflicts; biodiversity conservation; protected areas; social conflict; Argentina.

1 Conicet-Unmdp. Departamento de Geografía. Centro de Investigaciones Geográficas Socio-ambientales, Argentina. juanpablomorea@ gmail.com 


\section{Introducción}

La relación sociedad-naturaleza tiene vínculos históricos que datan desde los orígenes de la humanidad. Esta relación, que en sus inicios podía ser comparada con la de cualquier otra especie, se ha ido complicando en la medida en que el hombre ha aumentado su capacidad transformadora y dinamizadora del medio en el que vive (Isnard, 1975). La complejidad que ha adquirido esta relación puede ser abordada desde distintos puntos de vista, pero sin dudas se ha convertido en una relación problemática que tiene su origen en las acciones y reacciones del hombre hacia el medio y del medio hacia el hombre; y que en los últimos tiempos ha derivado en una fuerte conflictividad social con basamento en las disputas por el uso y la tenencia de la tierra.

La problemática territorial se encuadra dentro de la creciente tendencia por estudiar la denominada "cuestión ambiental o problemática ambiental". El interés por el abordaje de esta cuestión es visible en un gran número de disciplinas, que le han impreso enfoques muy variados, pero que suelen orientarse hacia la búsqueda de herramientas que posibiliten hacer frente a los problemas de desarrollo de la sociedad moderna (Galafassi, 2002).

El origen de la problemática territorial puede ser atribuido al incremento poblacional, al desarrollo de los núcleos urbanos, y a la expansión de las actividades económicas y productivas que han impulsado a la conquista de nuevos espacios y a la reconversión o refuncionalización de muchos territorios. Puede ser entendido también, en el marco de los cambiantes contextos políticos, las crisis económicas mundiales y los vaivenes de la economía globalizada, como principales promotores de los cambios de tendencias en el uso del suelo y el aprovechamiento de los recursos.

Las problemáticas territoriales tienen su manifestación más concreta entonces, como resultado de las distorsiones de la relación sociedad-naturaleza y actualmente pueden tener foco en casi cualquier tipo de espacio geográfico. Sin embargo, es innegable que las problemáticas más significativas tienen lugar en espacios de gran interés para el hombre y de alto valor para la conservación de la biodiversidad.

La manifestación problemática de la relación sociedad-naturaleza se ha desarrollado en los últimos tiempos, al llevar al extremo la premisa del dominio de la naturaleza para el crecimiento ilimitado, sustentado en una racionalidad económica e instrumental. En la visión de Leff (2005) hemos atravesado un proceso de cinco siglos de economización del mundo que culmina con su saturación y el límite de su extrema voluntad de globalizar el planeta traduciendo todos sus elementos a los códigos de la racionalidad económica.

La economía afirma el sentido del mundo en la producción; la naturaleza es cosificada, desnaturalizada de su complejidad ecológica y convertida en materia prima de un proceso económico; y los recursos naturales se vuelven simples objetos para la explotación del capital (Leff, 2005). En la medida en que el hombre ha desarrollado sus fuerzas productivas y extendido su dominio a través de la ciencia y la tecnología, se ha debilitado el lugar de la naturaleza en esta relación, a tal punto que algunos autores consideran que es posible "analizar a la historia humana como un proceso de emancipación gradual frente a los datos del medio ambiente y a las fuerzas naturales" (Cardozo \& Pérez Brignoli, 1984, p. 16).

Pero a la vez que el hombre adquiere mayor control sobre las fuerzas naturales, el gran desarrollo de las fuerzas productivas y la consolidación de la idea del progreso ilimitado han afectado tanto los procesos ambientales globales que hoy nos enfrentamos ante una crisis ambiental global. Esta transformación sin límites de la naturaleza:

(...) se vuelve contra sí misma y contra el hombre, pasando de una primera imagen confortable (una naturaleza que entrega todos sus recursos al servicio del confort humano) a una segunda aterradora (una naturaleza, que degradada por la propia acción humana, ya no puede brindar confort y se vuelve hostil), todo inscripto en un mismo proceso autoalimentado y construido sobre el mismo fundamento ontológico: la mediatización del mundo a través de una razón que lo instrumentaliza para la dominación constante del hombre sobre la naturaleza (Galafassi, 2012, p. 3).

Históricamente cada sociedad construye su espacio social o tiene un espacio construido que le es propio. Este espacio social necesita ser defendido y reproducido y cada sociedad busca hacerlo a través de los poderes del Estado, el poder político o el poder económico (Lefebvre, 1974). Este proceso de reproducción del espacio social en un contexto de una economía globalizada induce a una homogeneización de los patrones de producción y de consumo y materializa la idea del crecimiento ilimitado. 
Pero este crecimiento ilimitado choca con los límites de la propia naturaleza. La expansión de las sociedades hacia nuevos territorios genera una competencia y una disputa creciente por el espacio. En las sociedades modernas el espacio no es más un bien de uso, es una mercadería que se presta a todo tipo de fructuosas especulaciones. Bajo estas condiciones el espacio se produce y se consume (Harvey, 2004; Theodore, Peck, \& Brenner, 2009; Galafassi, 2012; Carlos, 2014).

La problemática territorial actual parte por supuesto, de los impactos y consecuencias directas sobre el ambiente de este modelo de crecimiento ilimitado y de producción del espacio en un contexto de capitalismo global (Harvey, 2004; Leff, 2005). El proceso de expansión de las fronteras urbanas y productivas y la cada vez menor disponibilidad de espacios genera una fuerte competencia por el uso del suelo y la tenencia de la tierra. Paralelamente, el interés y la preocupación por la conservación del ambiente ha cobrado fuerza en los últimos años, impulsando convenios y estrategias a nivel global que buscan fundamentalmente paliar los desequilibrios e impactos ambientales, y que proponen la consolidación y la ampliación de los sistemas de espacios protegidos como principal herramienta para conseguirlo (Convenio sobre la Diversidad Biológica; Objetivos de Desarrollo Sostenible de las Naciones Unidas; La Estrategia Mundial para la Conservación de la Unión para la Conservación de la Naturaleza).

Sin embargo, la pretensión de consolidar estrategias vinculadas a la conservación de la biodiversidad se enfrenta al expansionismo económico-productivo como principal amenaza, en una relación que le presenta dos grandes conflictos: la dificultad de expandir la red de espacios bajo protección; y la perdurabilidad a largo plazo de los espacios protegidos existentes.

La situación política actual obliga a la búsqueda de nuevas lógicas que habiliten el uso y la refuncionalización de estos lugares de forma encubierta o solapada. Se trata de lo que algunos autores han definido como una nueva fase de acumulación de capital, de nuevos procesos de cercamientos y de acumulación por desposesión (Harvey, 2004; Collective, 2012; De Angelis, 2012; Seoane, 2012) que ya no tienen que ver con la instalación de los principios de la sociedad de mercado "se trata es de expandir los espacios alcanzados por la propiedad privada o recuperarse en aquellos ámbitos en los cuales había tenido que ceder cierto terreno" (Galafassi, 2012, p.5).

En este contexto, los espacios protegidos se erigen quizás como el máximo exponente de los territorios no alcanzados totalmente por el sistema de producción. Estos territorios han logrado constituir sus propias reglas a través de un marco legal que los avala y mediante el establecimiento de límites y un sistema de gestión y administración diferenciada. Independientemente de la jerarquía administrativa, funcionan como unidades territoriales que poseen un cierto grado de autonomía respecto de la administración y gestión del resto de los territorios de un país.

Pero justamente son estos mismos espacios los que acumulan las mayores riquezas demandadas por las fuerzas económicas y productivas en la actualidad. Esta nueva lógica expansionista sigue buscando recursos naturales y biodiversidad pero no únicamente con fines extractivistas o de producción primaria. Estos espacios de reserva de naturaleza son valorados para fines habitacionales, turístico-recreativos, por los servicios ecológicos que pueden prestar y como fuente de riqueza genética.

Hemos vivenciado en tiempos recientes debates en torno a nuevas formas de utilización y aprovechamientos de estos espacios bajo construcciones conceptuales como el desarrollo sustentable, la explotación conservacionista, o la economía verde. Incluso es posible hablar de paradigmas emergentes como la economía ecológica o la economía ambiental (que aunque distintas en sus principios comparten el surgimiento a raíz de la crisis ambiental) que buscan formas de mensurar los factores ambientales dentro del racionalismo económico.

Sin embargo estas visiones han tenido numerosas críticas. La principal, referida a que el desarrollo sustentable no genera una revalorización del capital natural que sea realmente efectiva; ve a la humanidad fuera de la naturaleza, y a la naturaleza como un recurso o capital a ser explotado, y sólo le asigna la necesidad de mantener el desarrollo dentro de los límites de capacidad de carga del planeta (Vicencio Murillo, 2012). Las posturas más críticas ubican al discurso del desarrollo sustentable dentro de las nuevas lógicas del capital, que esconden bajo una supuesta sensibilidad ambiental una intención de instalar la idea de que todo espacio o recurso debe formar parte del sistema productivo. En palabras de Leff (2005):

La nueva geopolítica de la sustentabilidad se configura en el contexto de una globalización económica que, al tiempo que lleva a la desnaturalización de la naturaleza -la transgénesis que invade y transmuta tecnológicamente la vida-, con el discurso del desarrollo sostenible promueve una estrategia de apropia- 
ción que busca "naturalizar" -dar carta de naturalización- a la mercantilización de la naturaleza. En esa perversión de "lo natural" se juegan las controversias entre la economización de la naturaleza y la ecologización de la economía (p.3).

Lo que está en juego en definitiva es la refuncionalización o adaptación de estos territorios, otrora excluidos, a las necesidades del sistema productivo. Esta refuncionalización se produce en el marco de conflictos sociales entre quienes bregan por la preservación de estos territorios y quienes pretenden imponer el desarrollo de cualquier tipo de actividad que sea "más rentable" en términos económicos.

Las fuerzas económicas y de capital en general avanzan más rápido que las estructuras legales e institucionales y aprovechan debilidades en estos aspectos para avanzar sobre nuevos territorios. Asimismo, utilizan su posición de poder para presionar sobre las estructuras del Estado o del poder político, llegando si es necesario, a comprar voluntades para obtener permisos, habilitaciones, concesiones y hasta cambios en la legislación o los códigos de ordenamiento territorial. Este nueva lógica es más plausible en regiones o países donde las condiciones socio-políticas y los marcos jurídicos son más endebles.

Latinoamerica en su conjunto se ha convertido, en consecuencia, en una de las principales regiones foco de estos procesos (Seoane, 2012). La situación reflejada en las líneas anteriores permite establecer como hipótesis de trabajo que la expansión territorial de las actividades económicas se ha convertido en una de las principales amenazas para la conservación de la biodiversidad, produciendo en la actualidad visibles problemáticas en numerosos espacios protegidos, que pueden comprometer verdaderamente su viabilidad a largo plazo. En Argentina, la problemática territorial asociada a disfuncionalidades entre los usos productivos y la conservación del ambiente se ha manifestado en ciertos sectores del país, pudiendo mencionarse algunos ejemplos paradigmáticos. Por ello, tomando como punto de partida la situación de este país, el presente trabajo busca analizar críticamente la problemática territorial en torno a la conservación de la biodiversidad en espacios protegidos, identificando los principales procesos regionales, sus impactos sobre áreas de alto valor ecológico y paisajístico, y la amenaza que constituyen para la conservación de la biodiversidad.

\section{Método de trabajo}

El abordaje seleccionado para este trabajo responde a un diseño de tipo flexible que permite combinar en una misma investigación distintas perspectivas teóricas. En este caso permitió aunar estrategias metodológicas como la investigación documental con el estudio de casos. La elección de esta perspectiva metodológica responde a la necesidad de articular por un lado, una visión generalista que permita caracterizar fenómenos y problemáticas a nivel nacional y regional; y por otro, la necesidad de identificar las distintas formas en que estas problémáticas adquieren, solo posible a través del conocimiento de casos particulares.

Como primera etapa del abordaje se realiza una exahustiva revisión bibliográfica de índole crítica-analítica con el fin de realizar una interpretación de la relación sociedad-naturaleza que afronta el desafío de articular satisfactoriamente el binomio uso-conservación. Para ello se buscó caracterizar y entender las nuevas lógicas que impulsan el proceso de expansión capitalista en el contexto global y su manifestación problemática en el territorio Latinoamericano, y particularmente tomando como caso de estudio el territorio argentino.

Para analizar el caso argentino fue necesario identificar las principales actividades económicas que han propiciado procesos de expansión territorial en los últimos años. Estos procesos fueron dimensionados mediante datos estadísticos provenientes de instituciones oficiales (Ministerio de Planificación, Inversión Pública y Servicios, Ministerio de Ambiente y Desarrollo Sustentable de la Nación, Sistema de Información Ambiental Nacional; Bolsa de Comarcio de Rosario, Auditoria General de la Nación, Administración de Parques Nacionales) y también a partir de diversos estudios y evaluaciones científicas que se han ocupado de analizar estos procesos expansivos en distintas regiones del país.

Para lograr analizar el impacto de estos procesos sobre el ambiente y la conservación de la biodiversidad, se realizó un abordaje de casos emblemáticos en espacios protegidos. Con el objetivo de obtener una perspectiva de la situación nacional se buscó analizar casos de las regiones más importantes del país, tanto para el desarrollo de actividades económicas como por su riqueza en materia de biodiversidad. La identificación y selección de estos casos emblemáticos responde, en parte, a la investigación documental, pero también es resultado de investigaciones previas realizadas, fundamentalmente en las provincias de 
Buenos Aires y Río Negro, que han permitido identificar la influencia que la expansión de ciertas prácticas económicas han tenido en estos espacios en tiempos recientes.

Las principales fuentes utilizadas para esta etapa del abordaje pueden dividirse en tres grandes grupos. Aquellas que presentan aportes sobre la situación a nivel país (Almirón et al, 2007; Galafassi, 2012; Morea, 2014a; Morea, 2014b; Morea, 2016a); aquellas que reflejan la situación en distintas zonas o ecorregiones del país (Galafassi, 2013; Bendini et al, 2015; Zarrilli, 2016); y aquellas que representan casos de particulares de provincias o espacios protegidos (arembaum \& Anastasio, 2005; Brown et al, 2007; Schmidt, 2012; Galafassi, 2014; Paz et al, 2015; Guerrero y Peyroti, 2016).

La última etapa del abordaje consistió en un análisis de las iniciativas y estrategias de conservación impulsadas a nivel país. El objetivo de este análisis fue permitir interpretar y entender la capacidad de acción y de respuesta frente a esta problemática y establecer algunas tendencias a futuro. Dimensionar la capacidad de acción o las debilidades del Estado nacional en este aspecto, se presenta como un análisis importante para poder evaluar el verdadero sentido de amenaza que la expansión de las actividades económicas representa para la conservación de la biodiversidad, tal como se expresará en la hipótesis de trabajo.

\section{Resultados}

\subsection{Procesos expansivos regionales, conservacionismo y problemática territorial en Argentina}

Argentina es un país con larga tradición en materia de conservación de la biodiversidad. Su gran extensión territorial y la gran diversidad de climas y ambientes han favorecido el establecimiento de numerosos espacios protegidos. Al igual que ha ocurrido en la mayoría de los países, el proceso de conformación del actual sistema de espacios protegidos ha sido gradual. Se ha pasado de un primer periodo en donde este tipo de espacios surgían fruto de donaciones de tierras en zonas alejadas, a una etapa más reciente en donde la creación ha seguido los criterios de la biología de la conservación.

Con el transcurrir de los años se han creado ministerios, secretarias y organismos específicos dedicados a la gestión de los espacios protegidos; se han elaborado planes y documentos para mejorar su gestión, y se ha desarrollado un Sistema Federal de Áreas Protegidas [SIFAP]. Sin embargo, la gestión y la efectividad en el manejo de los espacios protegidos en Argentina sigue siendo muy deficitaria, fundamentalmente por la ausencia de un ordenamiento territorial, la falta de financiamiento, deficiencias en las instalaciones y equipamientos, y por debilidades institucionales (Morea, 2014b).

La problemática territorial manifiesta en los apartados anteriores también se produce en Argentina, pudiendo citarse ejemplos concretos en distintas provincias y regiones del país. Esta problemática tiene su origen en un proceso expansionista que se ha desarrollado en torno a las mega explotaciones de actividades como la minería, la industria hidrocarburífera, la producción de soja y maíz, el desarrollo inmobiliario, y las industria maderera y algodoneras.

Este proceso expansionista general posee particularidades de acuerdo al tipo de acividad y a la región del país involucrada. No obstante ello, la amenaza para la conservación de la biodiversidad en Argentina puede sintetizarse en dos importante procesos: la deforestación, y la transformación de espacios naturales. En los últimos 15 años la elevada cotización de ciertos productos en el mercado internacional ha propiciado la expansión de las fronteras agrícolas e industriales induciendo a estos dos grandes procesos.

Las características de los territorios regionales han dado lugar a distintos tipos de actividades que han reflejado estos procesos expansivos de distinta manera y con características particulares. En la Figura 1 se esquematizan las divisiones regionales del país y la conformación actual del sistema de espacios protegidos.

En las zonas de selvas y bosques norteños, por ejemplo, la industria madedera es la que induce a la deforestación al no respetar los procesos naturales de recuperación de las explotaciones ya instaladas, incitando a la expansión mediante la ocupación irregular de tierras y al deforestar relictos de monte natural para reforestar con pino y eucalipto (Barembaum \& Anastasio, 2005; Schmidt, 2012). Esta situación ha generado que las explotaciones madereras se hayan expandido, ocupando una gran proporción del territorio nacional (Figura 2). 
Figura 1. Sistema de Espacios Protegidos y Ecoregiones de Argentina

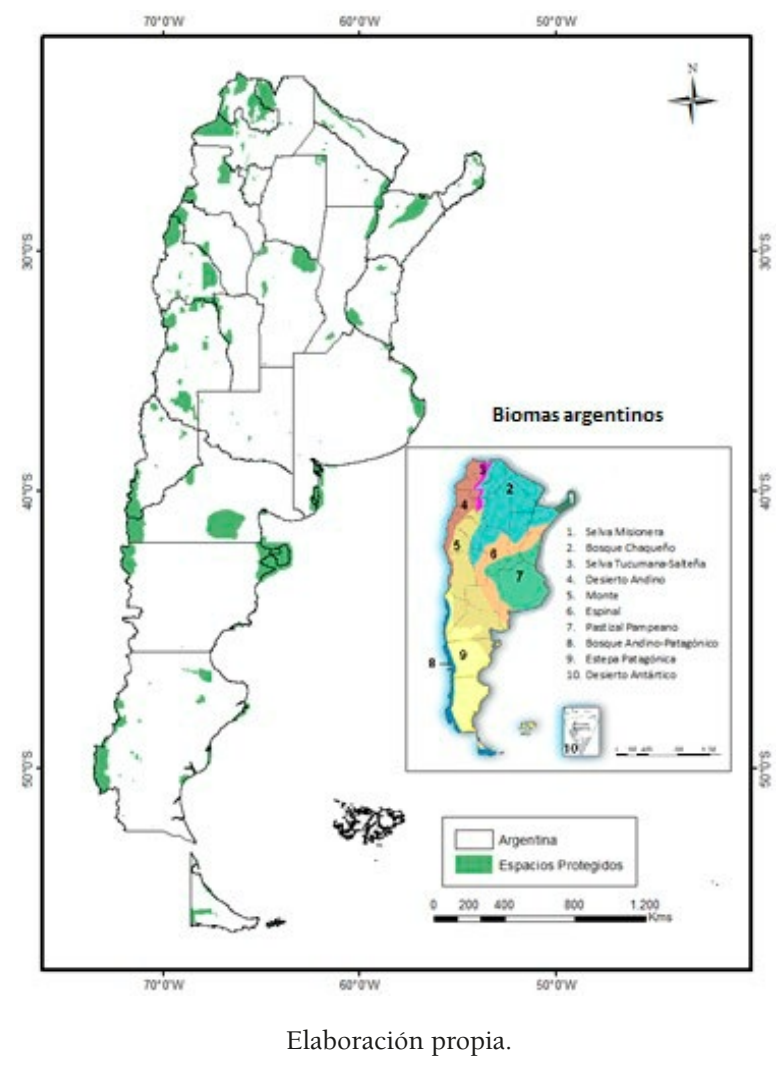

Figura 2. Zonas de producción forestal de Argentina

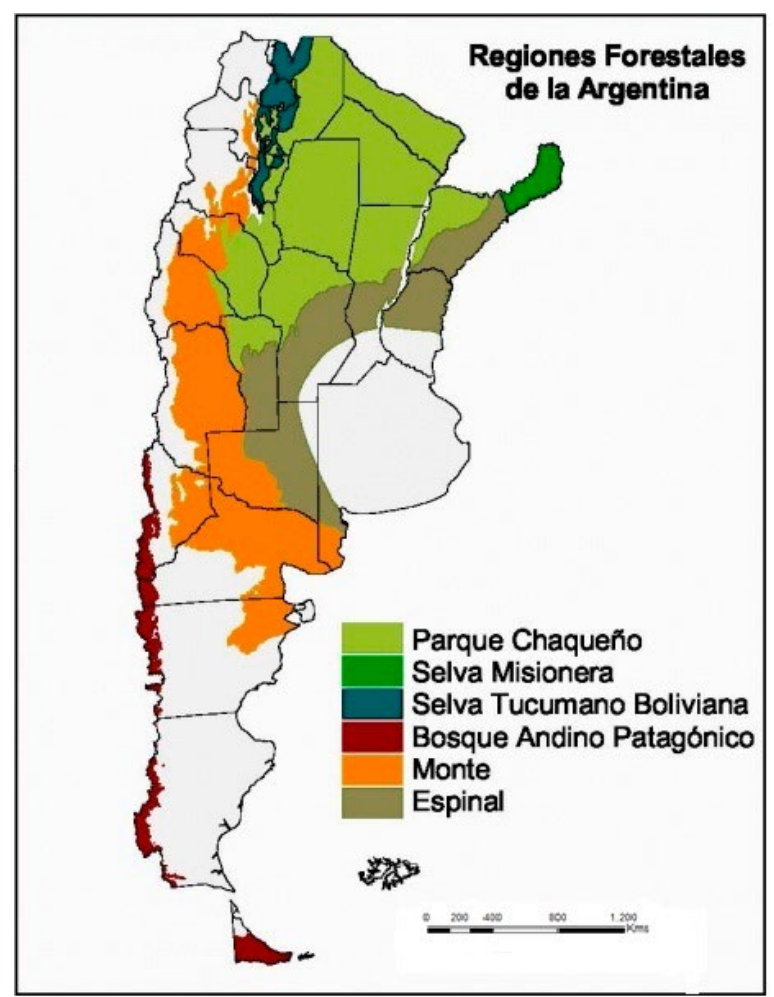

Fuente: Sistema de información ambiental nacional, 2015. 
En la zona del Gran Chaco, la superficie desmontada anualmente es la más grande de Argentina. En este caso, además de las explotaciones madereras, las actividades que generan esta situación son la implantación de cultivos de soja y maíz, la industria algodonera, y la ganadería intensiva, que desplazadas de la Región Pampeana se han extendido hacia el norte del país (Zarrilli, 2016). Una muestra de esto lo representa la zona del Noroeste argentino (incluyendo a las provincias de Salta, Tucumán, Santiago del Estero, Catamarca Jujuy y Chaco) donde la superficie cultivada con soja se ha incrementado en un 76,1\% entre 2001 y 2011 (Paz, Lipshitz, Zerda, \& Tiedemann, 2015). En la Figura 3 se representan las producciones de soja y algodón.

Figura 3. Zonas de producción de Soja y Algodón en Argentina
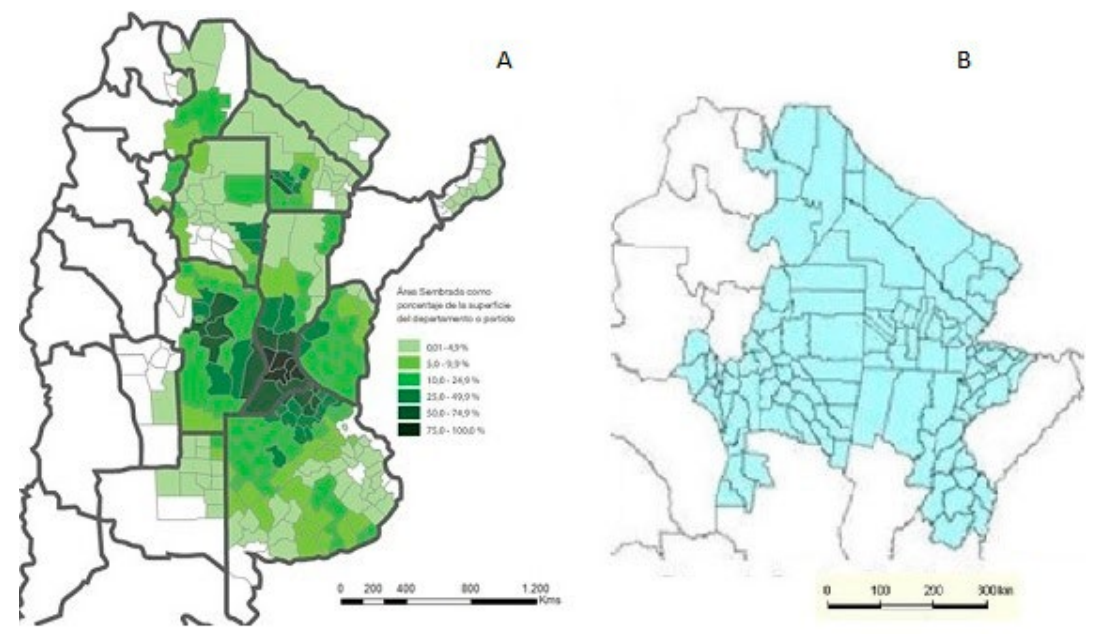

Fuente: A) Cultivos de soja. Bolsa de comercio de Rosario, Argentina, 2015; B) Producción de algodón. Zarrilli, 2016.

Por otro lado, en la Región Pampeana y Centro del país donde históricamente se ha desarrollado la ganadería y la agricultura de cultivos muy variados, el alto valor internacional de la soja en los últimos años ha generado una explotación continua sin rotación que ha colonizado una gran superficie de tierra. La cantidad de hectáreas sembradas con soja ha experimentado un crecimiento continuo en los últimos 35 años que consecuentemente ha propiciado un importante proceso expansivo o colonizador de tierras para cultivo. En el Gráfico 1 se refleja el crecimiento de la producción sojera del país en dicho periodo.

Gráfico 1. Producción de soja en la República Argentina, 1991-2016

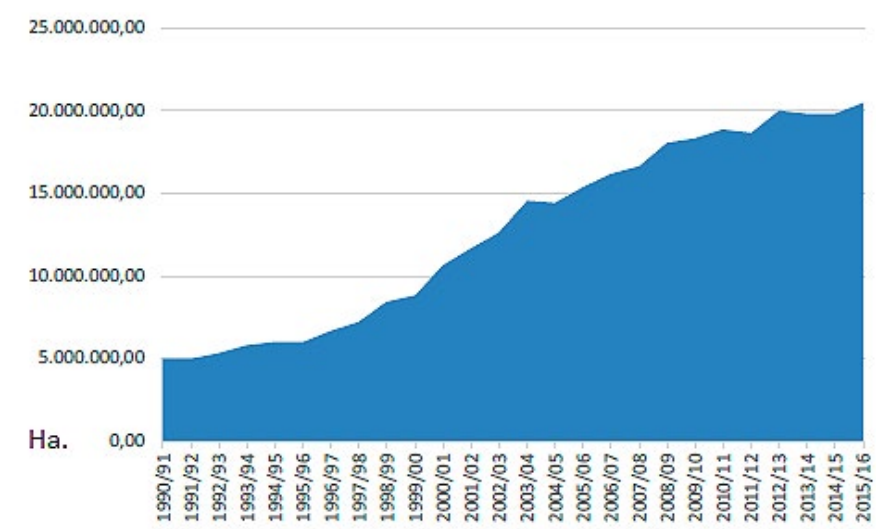

Fuente: Zarrilli, 2016.

Este proceso expansivo se ha generado especialmente en los últimos quince años, ante la degradación y el agotamiento de la tierra que generó este modelo de explotación. Se ha producido entonces, una expansión hacia zonas de sabana y bosques naturales e incluso hacia las banquinas de rutas y caminos (Almirón et al., 2007; Bendini, Steimbreger, \& Preda, 2015). 
La Región Patagónica, que se extiende desde el Centro hacia el Sur del país, presenta sus particularidades y los procesos expansivos han estado vinculados al desarrollo inmobiliario y a las actividades mineras y petrolíferas. El modelo de latifundios tiene sus orígenes a finales del siglo XIX con el fin de conquistar tierras que estaban en manos de los pueblos originarios y para la producción de lana y ganado ovino. Pero en los últimos tiempos este proceso ha mutado hacia una nueva lógica relacionada con procesos de desarrollo inmobiliario. La Patagonia Argentina ha sido principal objetivo de los capitales concentrados a nivel mundial que han comprado grandes extensiones territoriales, ya sea por su valor como recursos turísticos o paisajísticos o por los recursos naturales estrategicos que albergan.

En los últimos años se han presentado conflictos sociales con las comunidades locales en torno a las tierras que han adquirido grandes empresarios como Benetton, Ted Turner, George Soros, Perez Companc, Amalia Lacroze de Fortabat o Marcelo Tinelli. Conflictos surgidos en general de la apropiación ilegal o abusiva de recursos naturales, servidumbres de paso, o extensión indebida de los límites de los campos (Galafassi, 2013).

Otra actividad que genera grandes problemáticas territoriales es la actividad minera. Esta actividad se desarrolla en la Patagonia Andina y hacia el Norte en las Provincias de San Juan, la Rioja y Catamarca. Con la flexibilización de las Leyes mineras en la década de 1990, Argentina pasó de un esquema de explotación de escala pequeña a un modelo de megaminería a cielo abierto. Este modelo necesita de la ocupación de grandes terirtorios, la construcción de caminos y la disposición de grandes cantidades de agua. La instalación de estas minas produce la destrucción y contaminación de recursos en una extensa área de influencia y en ocasiones debido a la cercanía a espacios protegidos afectan recursos de gran importancia biológica (Almirón et al., 2007).

La última gran actividad que conforma el núcleo básico del proceso expansionista es la pretolífera. En Argentina se instala con fuerza desde 1922 con la creación de la empresa Yacimientos Petrolíferos Fiscales (YPF) con presencia fundamentalmente en la Patagonia y en algunas zonas del Noroeste del país. El principal factor de amenaza de esta actividad se produce en tiempos recientes a partir de un contexto internacional de agotamiento de los pozos tradicionales y la creada necesidad de encontrar nuevas fuentes de abastecimiento. Esta situación ha conducido a la exploración de nuevos territorios con potencial para la actividad y a la instalación de nuevos pozos petrolíferos. Algunos de ellos se han realizado en zona con alto valor natural y paisajístico, en zonas cercanas a áreas de reserva, y en ocasiones al interno de espacios protegidos.

Otro caso particular que merece ser destacado debido a los grandes procesos de expansión que tienen lugar, es la zona costera Argentina. Esta zona no se constituye oficialmente como una Región del país, pero posee características propias que merecen ser analizadas particularmente. Históricamente las poblaciones se han asentado en las cercanías de espacios marítimos y fluviales y esa tendencia se ha ido acrecentando con el paso de los años. Desde la década de 1990 hasta la actualidad se ha registrado una importante migración hacia las zonas costeras y sus proximidades, y en la actualidad un gran porcentaje de la población urbana vive en ciudades costeras (Desa, 2010). La presión antrópica sobre estos espacios es muy fuerte debido no sólo al significativo número de habitantes que estas zonas concentran sino además a la gran variedad de actividades y usos que allí se desarrollan.

Si bien es cierto que la interfaz marino-costera nunca ha sido el principal foco de atención en materia de conservacionismo, en los últimos años se han incrementado las estrategias de conservación en este tipo de espacios a nivel global, y en Argentina actualmente existen 45 espacios protegidos marino-costeros. Esta estrategia de conservación choca con los procesos de expansión urbana, que ante la escasez de espacio en las grandes ciudades, busca refuncionalizar otros territorios para transformarlos en nuevos proyectos inmobiliarios.

En Argentina al igual que en muchos países de la región estos procesos se han dirigido particularmente hacia zonas catalogadas como "más verdes" o "más naturales" para crear una alternativa habitacional y recreativa que escape a las grandes concentraciones que presentan las principales urbes Latinoamericanas. Estos mega proyectos inmobiliarios se han instaurado bajo la figura de barrios cerrados, country, clubes de campo, entre otros, y han ido colonizando grandes porciones de territorio, principalmente en la provincia de Buenos Aires y la Región Centro del país.

Es destacable que en los últimos años este fenómeno ha cobrado importante dimensión en las zonas costeras, debido a su alto valor paisajístico y su potencial para las actividades turísticas y recreativas. Pero 
justamente son estos espacios los que concentran mayor diversidad biológica, son áreas que cumplen importantes funciones ambientales y son de gran importancia para numerosas especies de flora y fauna. La expansión de proyectos de este tipo ha ido cercando a muchos espacios protegidos y se vislumbran actualmente algunos conflictos por la intención de muchos proyectos de instalarse dentro de los límites de estas unidades de conservación.

A consecuencia de todos estos procesos que tienen lugar en distintas zonas del país, no sólo se reduce la distancia entre las fronteras productivas y los espacios protegidos existentes, sino que paralelamente se van reduciendo las muestras representativas de distintos hábitats que dejan de tener tamaño suficiente para crear futuros espacios protegidos o implementar otras estrategias de conservación. La conjunción de todos estos procesos regionales es una de las razones principales de que los espacios protegidos en Argentina se vean cada vez más amenazados, a punto tal, que muchos de ellos han comenzado a enfrentarse a fuertes conflictos internos que ponen en riesgo su funcionalidad actual y su viabilidad a largo plazo.

\subsection{Problemática territorial y conflcitividad social en espacios protegidos de Argentina}

El interés por llevar a cabo acciones para la conservación de la biodiversidad tiene importantes antecedentes a nivel mundial. El establecimiento de espacios protegidos o áreas de reservas, históricamente ha sido la principal estrategia para garantizar la consecución de los objetivos de conservación. Hoy en día ya no se habla de los espacios protegidos como unidades aisladas capaces de preservar la biodiversidad por sí mismas, sino que los debates actuales en el campo de la biología de la conservación plantean la necesidad de establecer sistemas integrados de espacios protegidos, corredores biológicos y ecorregiones; y en definitiva el objetivo principal de conformar una red global de reservas (Morea, 2014a).

Si entendemos que la conservación de la biodiversidad siempre se hizo sobre espacios que el capitalismo resignó (sea por desinterés o sea por conquistas de otros grupos sociales); la problemática hoy, ante la escasez y ante el alto grado de degradación del resto de los territorios, es que los espacios protegidos pasan a ser vistos como grandes áreas de reservas de recursos naturales de todo tipo. La geopolítica de la biodiversidad hoy plantea una lucha en donde el capital busca establecer nuevas reglas y un nuevo orden para poder expandir su área de influencia y empezar a dominar espacios excluidos del sistema productivo.

Los procesos expansionistas y las nuevas lógicas de la etapa actual del capitalismo han tenido fuerte influencia en Argentina y las problemáticas regionales descriptas anteriormente han generado disputas territoriales y numerosos conflictos sociales. Muchos de estos conflictos se han suscitado en torno a los espacios protegidos, en algunos casos ante la amenaza de desaparición, y en otros por incomptibilidades de uso internas o por vulneración de sus límites.

En ciertas ocasiones este avance se presenta como una amenaza de corto o mediano plazo, pero los conflictos del presente surgen ante una ya manifiesta parcial colonización de muchos de estos territorios que se han visto vulnerados por los intereses económicos. Ya son numerosos los casos en los que los permisos de uso y explotación de recursos se han otorgado -legalmente o de facto- sobre áreas de importancia biológica, reservas con bajo grado de protección e incluso sobre Parques Nacionales. De esta forma se han ido "expropiando" pequeñas y no tan pequeñas porciones de territorio que antes tenían fines de conservación, generando no sólo una reducción de las superficies protegidas, sino además una serie de impactos negativos y externalidades que afectan a otras áreas u otros recursos de importancia significativa.

En ocasiones, son las mismas permeabilidades de los sistemas de espacios protegidos, las debilidades institucionales y las deficiencias en las tareas de gestión y control las que han permitido una aparición cada vez mayor de actividades y prácticas no previstas en los objetivos de estas áreas de reserva. Pero también es cierto que los objetivos de los sistemas de espacios protegidos han cambiado y la tendencia de los últimos años se ha orientado hacia la aceptación de cierto tipo de usos no relacionados con la conservación.

Hoy en día es difícil pensar espacios protegidos sin contemplar la presencia humana y en los últimos años la planificación del uso público ha adquirido un gran protagonismo como principal estrategia para logar la articulación del binomio uso-conservación dentro de cada reserva (Morea, 2016b). Hemos pasado de espacios protegidos que sólo admitían actividades turísticas o ecoturísticas de bajo impacto, a espacios que conviven con actividades como la pesca, la agricultura, la ganadería, la minería e incluso, algunos de ellos comprenden espacios urbanos e industriales. 
Ante esta situación, podemos afirmar que los espacios protegidos (principal estrategia de conservación de la biodiversidad a nivel mundial) se ven amenazados por el expansionismo en una doble escala de análisis: la externa y la interna. La primera representada por el avance desregulado de las fuerzas de capital que pueden provocar la desaparición de estos espacios; y la segunda vinculada a la conflictividad interna de cada unidad. Los ejemplos que podrían citarse abundan (Araya Rosas \& Clusener-Godt, 2007; Brown, Malizia, \& Lomáscolo, 2007; Schmidt, 2012; Seoanne, 2012; Galafassi, 2013; Galafassi \& Roig, 2014) y sería imposible abarcar la totalidad de ellos en este trabajo. No obstante, es posible señalar algunos casos paradigmáticos que pueden ilustrar las formas y características principales que estos procesos han adoptado en Argentina.

Un caso emblemático del avance de las fuerzas productivas sobre áreas de reserva tuvo lugar en la Provincia de Salta. En esta Provincia la expansión de las fronteras agropecuarias y las talas de bosques han sido muy fuertes en las últimas décadas, generando grandes problemáticas y llegando al punto de comprometer a varios espacios protegidos (Schmidt, 2012). En el año 1995 el gobierno de esa provincia declaró una zona de casi 26000 hectáreas como "Reserva de General Pizarro", aunque efectivamente nunca se cumplió con la Ley ni se llevaron adelante acciones de gestión de ese espacio.

Esta inacción llevó en el año 2004 a un intento de desafectación del espacio protegido para lotear y vender las tierras en cuestión, y utilizarlas para la producción. A raíz de esta iniciativa se generó un conflicto social que tuvo repercusión a nivel nacional y movilizó a la defensa de este espacio y de los bosques salteños por parte de las comunidades locales, distintas ONGs y la sociedad en general (Schmidt, 2012). Como resultado y luego de mucho esfuerzo se logró realizar un convenio entre la provincia de Salta y el gobierno Nacional para crear en esta zona un espacio protegido nacional dependiente de la Administración de Parques Nacionales. La Reserva Nacional Pizarro se creó finalmente en el año 2012 y este caso se convirtió en un ejemplo de defensa del ambiente, aunque no debe desconocerse que representa un caso aislado y que los desmontes en el norte argentino continúan avanzando (Araya Rosas \& Clusener-Godt, 2007; Schmidt, 2012).

Otro conflicto importante que puede mencionarse tiene como protagonista a la actividad hidrocarburífera en las provincias de Río Negro y Neuquen y al Parque Nacional Nahuel Huapi (El primero en crearse en el país en 1903) y otros espacios protegidos adyacentes. En esta zona a partir del 2006 se comenzaron a realizar nuevas exploraciones hidrocarburíferas alrededor de distintas potenciales cuencas, algunas de las cuales estaban ubicadas en áreas de alto valor ecológico. La Cuenca de Somuncurá como también la de Nirihuau se encuentran emplazadas por debajo del Área Protegida Meseta de Somuncurá, un territorio de gran importancia por su biodiversidad y por reservas subterráneas de agua dulce. Además, la cuenca Nirihuau, que se extiende por territorios de las provincias de Río Negro y Chubut, se ubica a unos pocos kilómetros del Parque Nacional Nahuel Huapí y dentro de la recientemente creada Reserva de Biosfera Norpatagónica (Galafassi, 2013).

Los permisos de explotación de la cuenca fueron otorgados en 2008 lo que generó la reacción de las comunidades que habitan cerca de la zona, de organizaciones ambientalistas y de los pueblos originarios (especialmente los Mapuches) quienes reclamaban un derecho de ocupación histórica sobre esas tierras. A pesar de las denuncias, los recursos de amparo y las audiencias públicas que el gobierno provincial se tuvo que llevar adelante, sólo se consiguió demorar el proyecto y el plan de explotación se hizo efectivo a principios de 2009 (Galafassi, 2013).

Desde 2009 en adelante el conflicto continuó, primero con acciones de remediación ambiental que debieron aplicarse a consecuencia de los impactos del proyecto y finalmente con la revocación de los permisos de explotación en el año 2012 por incumplimiento en los contratos y falencias en el manejo de los recursos (Galafassi \& Roig, 2014). No obstante el freno a esta explotación, es preciso señalar que en 2011 se otorgó otra concesión en esta misma cuenca, esta vez en el sector sur perteneciente a la Provincia de Chubut, por lo que la zona sigue siendo afectada.

Las explotaciones de hidrocarburos sobre espacios protegidos en Argentina tiene otros antecedentes. Existen otros espacios protegidos que han experimentado procesos similares como el Parque Nacional Calilegua en Salta y el Parque Nacional San Guillermo en San Juan (Gavaldá \& Scandizzo, 2008).

Otro caso que merece ser destacado dentro de esta problemática es el de la Reserva de Biosfera de las Yungas en las provincias de Salta y Jujuy. Esta reserva es de gran importancia para la conservación de la diversidad biológica del país, pero a la vez tiene un alto valor para los sectores agrícolas, forestales y 
energéticos. La primera vez que esta zona entró en conflicto fue con la construcción del Gasoducto NorAndino que atravesó zona de bosques y de la cuenca del río Bermejo. El conflicto por la construcción del Gasoducto inició el proceso que desembocó en la creación de la Reserva di Biosfera de las Yungas (Brown, Malizia, \& Lomáscolo, 2007) como estrategia para buscar alternativas de producción sustentables o mas respetuosas del medio ambiente.

A pesar de la creación de esta reserva las actividades productivas y las comunidades que habitan dentro y cerca de la misma continúan siendo una amenaza para la conservación. Las actividades de explotación y transporte de hidrocarburos construyen ductos y caminos y dan lugar a otros impactos como la explotación forestal, la caza ilegal y el ingreso de ganado al interior del bosque. Los ingenios azucareros que se ubican dentro y en rededor de la Reserva de Biosfera generan impactos como la contaminación de los ríos y el aire, la deforestación y el drenaje de humedales y se estima que en total hay alrededor de 100.000 hectáreas dentro del área de influencia de la reserva que están en conflicto por esta situación. Por su parte, la actividad maderera se desarrolla en casi el 70\% de la superficie de la reserva y en general no han podido reconvertir su forma de producción a prácticas sustentables (Brown et al., 2007; Seoane, 2012).

Siguiendo con los ejemplos de Reservas de Biosfera, en la provincia de Buenos Aires vale hacer referencia a la problemática ocurrida en Mar Chiquita. Esta reserva -ubicada sobre el frente costero de dicha provincia- al igual que en el caso anterior posee un gran porcentaje de tierras de dominio privado y conviven con las actividades de conservación usos productivos como la ganadería, la agricultura, la pesca y el turismo. Más allá de los impactos que estas actividades generan, en los últimos años se ha desarrollado un proceso de expansión urbana sobre espacios de alto valor ecológico y paisajístico del frente costero en casi la totalidad provincia, que se ha visto reflejado en la proliferación de barrios cerrados y clubes de campo.

Dentro de la reserva de biosfera "Parque Atlántico Mar Chiquito" el conflicto se suscitó cuando en el año 2012 el gobierno municipal autorizó un cambio de uso del suelo, transformando una porción del territorio incluida dentro de la zona de transición de la reserva. Este espacio lindante con la laguna de Mar Chiquita pasó de uso rural a uso urbanizable y se autorizó el desarrollo del barrio privado "Lagos del Mar". El proyecto avanzó llegando a realizarce el trazado de las calles internas, la entrada principal y las instalaciones de luz, hasta que una medida judicial suspendió la continuidad de la obra por denuncias sobre los impactos ambientales y la ilegalidad de la aprobación de esta obra. Actualmente el conflicto sigue sin resolución y la Justicia provincial debe dictaminar sobre la continuidad o no del proyecto.

Todos estos casos representan ejemplos claros de las amenazas externas que los espacios protegidos enfrentan. Estos grandes procesos que constituyen la escala o dimensión externa de la amenaza a la conservación de la biodiversidad en espacios protegidos derivan en muchos casos en la ocupación de territorios al interno de estos espacios. Pero no todos los casos están constituidos por ocupaciones ilegales, por el desarrollo de grandes proyectos de infraestructura o por procesos expansivos regionales.

En este punto es importante diferenciar los problemas emergentes de la escala interna de la amenaza a los espacios protegidos. Se mencionó previamente que los espacios protegidos se encuentran inmersos en una tendencia que los lleva a convertirse cada vez más en espacios multifuncionales e integrados a la sociedad. No debe olvidarse, sin embargo, que históricamente los usos turístico-recreativos y educativos siempre estuvieron presentes y estaban incluidos dentro de las funciones principales de estos espacios.

La aparición de otros usos y actividades pertenece a una etapa más reciente en donde se comienza a aceptar la idea de crear espacios menos restrictivos y se consolidan las clasificaciones y categorizaciones de las unidades de conservación de acuerdo a su nivel de protección. Se consolida a su vez el concepto de "uso público" para comprender todas aquellas actividades que se desarrollan dentro de un espacio protegido que no tienen que ver directamente con los objetivos de conservación.

Esta apertura de los espacios protegidos permite generar una integración entre estos lugares y la sociedad, fundamentalmente propiciando una mayor valoración y reconocimiento por parte de las comunidades que habitan cerca de ellos. El afianzamiento de esta tendencia persigue el objetivo de complementar las redes existentes de espacios protegidos, y a su vez lograr que la sociedad desarrolle un sentido de pertenencia que se materialice en una defensa de estos lugares. En un contexto de fuerte competencia por el espacio, la flexibilización de los requisitos para crear unidades de conservación se presenta como una alternativa viable para concretar el obejtivo de expasión de las redes existentes. Complementariamente, esta flexibilización -que redunda en la multifuncionalidad- permite contemplar los intereses y voluntades de las comunidades locales y se constituye en una estrategia para que sientan a estos espacios como propios. 
Pero estos objetivos que pueden ser concebidos realmente con una intención de mejorar el funcionamiento del sistema de espacios protegidos, implican la difícil tarea de compatibilizar actividades de uso y conservación. Permitir el desarrollo de actividades económicas dentro de estos espacios conlleva necesariamente a la aparición de impactos negativos, y significa dar lugar a la presencia de nuevas amenazas, que ya no son externas, e implican un riesgo mayor. Establecer los límites y el control de cada actividad pasa a ser una cuestión fundamental para evitar que las fuerzas económicas avancen cada vez más dentro de estos territorios, reduciendo el espacio dedicado a la conservación.

En consecuencia, la planificación del uso público con especial énfasis en el turismo, ha ganado mucha importancia en los últimos años, a punto tal que se han elaborado numerosos documentos, planes y propuesta metodológicas para abordar esta cuestión, derivados del Convenio Sobre la Diversidad Biológica, e impulsadas por organismos especializados en la temática como la Unión Mundial para la Conservación de la Naturaleza [UICN] o el Fondo Mundial para la Naturaleza [WWF] (Santos \& del Álamo, 2012; Morea, 2016b).

Lo cierto es que lograr la gestión y el control de las actividades y la integración con las acciones de conservación resulta una tarea difícil y la flexibilización de los marcos normativos de los espacios protegidos ha dado lugar a la ocupación ilegal y a la expasión indebida de ciertas actividades, que en muchos casos debieran estar prohibidas, y en otras, se desarrollan excediendo las capacidades establecidas. Estas problemáticas derivadas de la falta de planificación y gestión del uso público constituyen uno de los factores principales de la baja efectividad en el manejo de los espacios protegidos en Argentina (Almirón et al., 2007; Giaccardi \& Tagliorette, 2007; Auditoria General de la Nación, 2010; Morea, 2014b).

\subsection{Estrategias de planificación vinculadas a la conservación de la bidiversidad}

Ya en 2007 en un documento elaborado por la Administración de Parques Nacionales de Argentina [APN] se manifestaba la preocupación por el avance de las actividades del sector primario y la necesidad de desarrollar estrategias para paliar esta situación:

Hoy, desde la década anterior a esta parte, se está asistiendo a nuevas oleadas expansivas de las actividades del sector primario (agricultura industrial, biocombustibles, minería, hidrocarburos) estimuladas por la alta cotización internacional de sus productos. La enorme extensión, intensidad y potencial expansivo de sus impactos sobre el medio natural y la población rural está gestando en respuesta numerosas manifestaciones públicas de alerta. Medidas de gobierno que se encaminen a minimizar o compensar esos costos ambientales y sociales se están orientando en varios países del Continente hacia un Ordenamiento Territorial, que planifica la distribución en el espacio de tales actividades en expansión, resguardando a su vez las porciones de territorio donde se conserven muestras adecuadas del patrimonio natural y cultural de cada ecorregión (Almirón et al., 2007, p. 5).

Ante esta situación y en línea con lo expresado por Almirón et al (2007) se refleja la necesidad de frenar la expansión desregulada de las actividades económicas encauzando procesos de ordenamiento territorial que permitan identificar áreas de importancia biológica y cultural para expandir el porcentaje de tierras bajo protección. La necesidad de un ordenamiento territorial a nivel país se presenta como una estrategia para enfrentar la dimensión externa de la amenaza expansionista y responde a una tendencia mundial.

Argentina ha participado y ha sido protagonista de numerosos encuentros e iniciativas regionales e internacionales, adhiriendo a la mayoría de los convenios, estrategias y metas planteadas por los principales organismos preocupados por la conservación de la biodiversidad a nivel mundial. A partir del Convenio sobre la Diversidad Biológica el país ha generado su propia Estrategia Nacional y llevado adelante distintas iniciativas y proyectos en ese marco.

Pero muchos países de Latinoamérica transitan caminos similares y puede decirse que hay intenciones de trabajo conjunto que se reflejan en encuentros y convenios multilaterales. En 1997 se realizó el Primer Congreso Latinoamericano de Parque Nacionales y otras Áreas Protegidas en la ciudad de Santa Marta, Colombia y en 2007 se llevó a cabo el segundo en Bariloche, Argentina. En sus conclusiones, estos congresos han expresado como desafíos para la región la necesidad de consolidar los Sistemas de Áreas Protegidas; priorizar la sostenibilidad financiera de estos sistemas para garantizar su funcionamiento; propiciar que tengan mayor estatus político en la estructura gubernamental y promover estrategias de co-gestión a nivel bilateral o regional (Guerrero, Sguerra, \& Rey, 2007) 
En ese sentido puede decirse que Argentina ha logrado ciertos avances en los últimos tiempos. El financiamiento y el estatus gubernamental quizás sigan siendo los mayores déficits, pero en los últimos diez años se ha expandido el porcentaje de territorio protegido a través de la declaración de nuevas unidades de conservación, especialmente en categorías de protección menos estrictas como estrategia para complementar a los Parques Nacionales y otros espacios de alto nivel de protección. Se destacan dentro de esta estrategia la creación de nuevos espacios protegidos en la zona costera-marina, en las provincias de Santa Fe, Córdoba y La Pampa, y en las zonas del Gran Chaco o los Deltas. Conjuntamente la Ley General del Ambiente (Ley 25.675, 2002) y la Ley de Presupuestos Mínimos de Protección Ambiental de los Bosques Nativos (Ley 26.331, 2007) han facilitado el apoyo a estas estrategias.

Pueden mencionarse también iniciativas de manejo interjurisdiccional, como el Sistema Inter-Jurisdiccional de Áreas Protegidas Costero Marinas, con implementación 2010-2014 o el Parque Interjurisdiccional Marino Costero de la Patagonia Austral. Vale destacar además estrategias de integración regional como la creación del Parque y Reserva Binacional Argentino-Uruguayo; el corredor andino-norpatagónico (con Chile) y el corredor biológico de las yungas (con Bolivia).

Sin embargo, hasta el momento no existen iniciativas concretas que propongan un ordenamiento territorial a nivel país que permita implementar una política de consolidación nacional del sistema de espacios protegidos. La única propuesta destacada en los últimos años ha sido el Plan Estratégico Territorial [PET] lanzado en 2005 por el Ministerio de Planificación, Inversión Pública y Servicios (Argentina), con la intención de construir un modelo deseado del territorio nacional con proyección al 2016, basado en la integración de las visiones provinciales. Si bien este plan promovía un enfoque integrador, en realidad ponía mucho énfasis en la planificación de infraestructuras, relgando a un segundo nivel al resto de las necesidades del país (Almirón et al., 2007; Morea, 2016a).

El PET contó con la participación de la entonces Secretaría de Ambiente y Desarrollo Sustentable de la Nación [SAyDS], de la APN y de diversos organismos provinciales vinculados a la protección del ambiente y la conservación de la biodiversidad. Es destacable que estos organismos dentro de la etapa de diagnóstico identificaron las áreas con potencialidades ecológicas y paisajísticas; los espacios protegidos existentes; los corredores de conservación para conectar dichas áreas; y áreas no coincidentes con los espacios protegidos, pero que requieren cierto grado de protección (Morea, 2016a).

A pesar de ello, en la conformación del modelo deseado del territorio nacional sólo 14 de las 25 unidades administrativas territoriales del país proponen proyectos vinculados a la conservación del ambiente. Sólo 7 provincias proponen creación de nuevos espacios protegidos y sólo 5 proponen establecer corredores biológicos (Morea, 2016a). Por el contrario, los proyectos vinculados a la expasión de ciudades y al desarrollo de infraestructuras de apoyo para las actividades económicas son considerados prioritarios y están presentes en gran número a lo largo de todo el país.

En consecuencia, la mayoría de las iniciativas que buscan poner freno a la expansión desregulada siguen surgiendo de los organismos específicamente ocupados y preocupados por la conservación de la biodiversidad, que llevan adelante una política sectorial y que buscan consolidar una posición proactiva hacia la conservación de la biodiversidad. La úlitma propuesta en esta línea la constituye la "Estrategia Nacional sobre la Biodiversidad y Plan de Acción 2015-2020" elaborada por la entonces SAyDS (Hoy Ministerio de Ambiente) articulando con la Comisión Nacional Asesora para la Conservación y Utilización Sostenible de la Diversidad Biológica [CONADIBIO] -un ámbito multisectorial del cual participan organismos del Estado nacional y provinciales, representantes del sector científico y técnico y organismos de la sociedad civil, con competencias en diversas temáticas vinculadas directa o indirectamente con la biodiversidad-. Esta propuesta pretende establecer una visión renovada de la biodiversidad basada en un ordenamiento ambiental del país:

El ordenamiento ambiental del territorio es un instrumento clave para abordar el desarrollo sustentable del país y por eso ha sido un tema transversal a lo largo de los ejes de la Estrategia, fundamentalmente el Eje 1, Conservación y Uso Sustentable de la Biodiversidad y el Eje 4, Prácticas Productivas y de Consumo Sustentables (Secretaria de Ambiente y Desarrollo Sustentable, 2015, p. 11).

Entre las 21 metas nacionales propuestas pueden destacarse las que apuntan a la ampliación de la superficie protegida (13\% del territorio nacional, con una protección no menor del 4\% en cada ecorregión y en la zona costero-marina) y las que buscan consolidar prácticas sustentables en torno a las actividades económicas de mayor impacto como la pesca, la ganadería y la agricultura. No obstante, el documento es 
de elaboración reciente, y en el marco de un cambio de gobierno a nivel nacional, lo que impide valorizar su impacto. La aplicación de esta estrategia y el alcance de las metas establecidas dependerá en gran medida de una articulación permanente entre los distintos niveles de la administración del Estado, y de la existencia de un trabajo mancomunado con el sector productivo y las comunidades locales.

\section{Discusión}

El trabajo desarrollado presenta una mirada particular sobre una temática que ha cobrado gran interés en el ámbito científico-académico en los últimos años en Lationamérica, como es la problemática territorial-ambiental vinculada a los procesos de expansión económica.

Los resultados de este trabajo demuestran que estos procesos expansivos han tenido lugar a lo largo de todo el territorio argentino y han producido grandes transformaciones en las corberturas y el uso del suelo que están afectando significativamente al ambiente. Son numerosos los autores que han llevado a cabo estudios para dimensionar los impactos regionales de los cambios de uso del suelo impulsados por actividades primarias, en un proceso denominado como extrapampeanización o expansión extrapampeana, debido a la aparición de producciones típicas de la Región Pamepana en zonas del país tradicionalmente dedicadas a otras actividades (Galafassi, 2013; Galafassi \& Roig, 2014; Bendini et al., 2015; Paz et al., 2015; Zarrilli, 2016).

Como se mencionó en distintos apartados del estudio, este tipo de problemáticas no es únicamente propia de Argentina y pueden encontrarse procesos análogos y en ocasiones casi idénticos en la mayor parte de los países de Latinoamérica. Diversos autores han estudiado la similitud de los contextos políticos y socioeconómicos que ha atravesado la Región, como principal causa de la manifestación generalizada de los procesos expansivos, identificando a su vez, a la actividad hidrocarburífera, la soja, la explotación maderera, y algunas otras explotaciones de materias primas como principales impulsores de esta problemática (Leff, 2005; Boisier, 2014; Galafassi, 2014; Sabourin, Samper, \& Sotomayor Echenique, 2014; Gorenstein, 2015; Galloway et al., 2016).

Teniendo en cuenta este contexto, pueden destacarse algunos datos obtenidos en dos estudios, que reflejan la dimensión de esta problemática en Argentina. Bendini et al (2015) estimaron que entre 2002 y 201037.000 ha de pastizales y 42.000 de bosques y montes se perdieron a causa de la soja en el noroeste de la provincia de Córdoba; mientras que suman 600.000 ha de bosques las que fueron transformadas en áreas agrícolas en la provincia de Salta en los últimos 30 años. Por su parte, Zarrilli (2016) estimó que 73 millones de héctareas de bosque nativo se han perdido en el Gran Chaco argentino en menos de 50 años.

El interés de centrar la mirada en los espacios protegidos responde justamente a que estos espacios concentran las mayores riquezas naturales y muestras de biodiversidad. Los resultados presentados en este estudio demuestran como muchos de estos espacios han comenzado a sufrir vulneraciones y desafectaciones, principalmente a consecuencia de deficiencias en la gestión y débiles marcos institucionales que no son capaces de frenar el avance de los intereses económicos. Un estudio ejemplificatorio de esta situación fue el desarrollado por Guerrero y Peyroti (2016) donde se refleja que Córdoba es la segunda Provincia argentina con mayor porcentaje de su territorio bajo alguna figura de conservación alcanzando el $23,7 \%$ de cobertura. Sin embargo, sólo el $1 \%$ del espacio natural protegido dispone de programas de manejo.

Ya entre 2008 y 2009 algunos estudios realizados a escala planetaria alertaban sobre el acortamiento de la distancia entre los espacios protegidos y los centros urbanos más cercanos, con las consecuentes amenzas asociadas (McDonald, Kareiva, \& Forman, 2008; Mcdonald et al., 2009). Desde entonces, han proliferado los trabajos abocados a estudiar la relación entre las actividades de uso y conservación en espacios protegidos, fundamentalmente preocupados por encontrar alternatvas que permitan su subsistencia a largo plazo. La bibliografía es amplia y presenta casos de estudio de diversos países, en donde la planificación del turismo y otras actividades económicas, la evaluación de la efectividad en el manejo, o el diseño de nuevas metodologías de planificación son los principales ejes abordados (Geneletti \& van Duren, 2008; Santos \& del Álamo, 2012; Jasso \& Abellán, 2015; Lopes, Pacheco, Clauzet, Silvano, \& Begossi, 2015; Morea, 2016b).

En los últimos años se observan también muchos estudios que siguen un abordaje similar al de este trabajo y analizan los impactos de la expasión económica sobre los espacios protegidos en el contexto Latinoamericano, y también en otras regiones del mundo. Tal es el caso de la problemática de la defo- 
restación en el Amazonas y sus efectos sobre los espacios protegidos en Brasil (Barber, Cochrane, Souza, \& Laurance, 2014); los efectos sobre los espacios protegidos a consecuencia de los cambios de uso del suelo en el Amazonas peruano y en la península de Yucatán en México (García-Frapolli, Ayala-Orozco, Bonilla-Moheno, Espadas-Manrique, \& Ramos-Fernández, 2007; Miranda, Corral, Blackman, Asner, \& Lima, 2016); el análisis de las consecuencias de la ocupación humana en espacios protegidos de Perú (Dourojeanni, 2014); o el análisis de los efectos negativos que los actuales y futuros cambios de uso del suelo podrían tener en torno a los espacios protegidos en Estados Unidos (Hamilton et al., 2013).

En definitiva, se aprecia que las problemáticas analizadas en este trabajo sobre algunos espacios protegidos de Argentina, también se presentan en otros países y en otros contextos. Esto pone de manifiesto la importancia que tendrá en los años venideros focalizarce sobre las dinámicas y cambios de uso del suelo como un factor indispensable a la hora de establecer estrategias vincualdas a la conservación de la biodiversidad.

\section{Conclusiones}

A partir del trabajo realizado podemos arribar a ciertas conclusiones que nos pueden acercar a comprender de manera más cabal algunos de los aspectos más significativos de la problemática territorial en torno a la conservación de la biodiversidad en Argentina. Quizás uno de los aportes más destacados sea la caracterización de la problemática territorial y los conflictos asociados a partir de la relación disfuncional sociedad-naturaleza como un devenir de procesos de escala regional, nacional y global.

Pero esta disfuncionalidad se manifiesta en un contexto global con características renovadas y nuevas lógicas que en América Latina parecen haber cobrado cierta homogeneidad. El contexto actual sigue pergeñando una relación en donde cada país asume, se le impone, o cumple un rol determinado, necesario para el funcionamiento del sistema global. En este juego de roles, la provisión de biodiversidad, de recursos naturales y fundamentalmente de tierras aptas para la producción, pareciera ser nuevamente el papel desempeñado por esta Región. Quizás no ya mediante una dominación política tan manifiesta; sin las características del modelo imperialista de otrora, o sin la presencia de gobiernos de facto y regimes autoritarios; pero sí a través de una dominación económica impulsada por los países más desarrollados e implementada por las principales fuerzas económicas y corporaciones multinacionales.

Los impactos de esta relación disfuncional hace varios años comienzan a manifestarse, al punto tal, que la problemática territorial y el conflicto ambiental están en la agenda de todos los países, expresados mediante un dualismo conservación versus desarrollo, o expansionismo versus conservacionismo. Las relaciones de poder tan desiguales en ciertas zonas de Argentina hacen cobrar vida a la idea del crecimiento ilimitado y del capitalismo voraz, y ponen de manifiesto los grandes desequilibrios que este tipo de situaciones generan en los sistemas territoriales del país. Los documentos y los casos analizados nos permiten observar que las estrategias tradicionales en materia de conservación ya no son suficientes y muchos de los espacios y los derechos ganados en materia de conservacionismo han sido vulnerados, y muchos otros están fuertemente amenazados. En Argentina este proceso expansionista ha adoptado distintas formas y distintas características según contextos regionales, pero a través de los casos abordados puede observarse que esta problemática se extiende a lo largo y lo ancho del país, pudiendo citarse ya numerosos ejemplos de avasallamientos sobre espacios de importancia para la conservación de la biodiversidad y para el funcionamiento equilibrado de un sistema territorial nacional.

Del análisis de casos se desprende también la importancia de entender las amenazas a la conservación de la biodiversidad en una doble escala o dimensión. La consolidación de las estrategias en materia de conservación requiere de la expansión de las superficies protegidas, disputándole el dominio de la tierra a las fuerzas del mercado. Pero requieren también, de una defensa de los espacios existentes y de la consecución de un adecuado manejo de cada unidad de conservación, y de la consolidación de los sistemas de espacios protegidos. La multiplicidad de formas que el expansionismo económico adopta hace indispensable la implementación de estrategias que sepan abordar esta doble dimensionalidad.

Hasta el momento, si bien se ha logrado progresar con varios proyectos e iniciativas en distintas regiones del país, todavía no se puede hablar de la existencia de verdaderos procesos de alcance nacional. De hecho, el porcentaje de superficie protegida del país aun se mantiene por debajo de las metas establecidas por los convenios internacionales, y si nos referimos al manejo de los espacios protegidos existentes, podemos identificar grandes deficiencias en la gestión y en el alcance de los objetivos de conservación. 
Por otro lado, parece haber consenso en varios de los documentos relevados en que el ordenamiento territorial y/o ambiental se presenta como una herramienta fundamental para lograr encauzar un mejor funcionamiento del sistema territorial argentino, poniendo en valor las áreas de importancia para la conservación y rediseñando el sistema económico-productivo. Sin embargo, los intentos de acercamiento a propuestas de este tipo son muy incipientes y no se denota una verdadera articulación entre todos los agentes, actores y sectores fundamentales para la materialización de un plan que tenga posibilidades reales de ser aplicado y concretado en el territorio.

Queda claro igualmente que la búsqueda de propuestas con una visión integral de la problemática territorial es una tendencia que viene evolucionando y se consolidará en los próximos años, y tendrá como principal desafío lograr finalmente la tan dificultosa armonización del binomio uso-conservación. Los espacios protegidos, como principal estrategia de conservación de la biodiversidad, seguirán siendo territorios de disputa y espacios de prueba para la articulación de la relaciones sociedad-naturaleza.

\section{Referencias}

Almirón, M., Balabusic, A, Bosso, A, Bukart, R., Carminati, A., Carpinetti, B., ... Somma, D. (2007). Las Áreas Protegidas en la Argentina. Herramienta Superior para la conservación de nuestro patrimonio natural y cultura (APN y FVSA). Buenos Aires.

Araya Rosas, P., \& Clusener-Godt, M. (2007). Reservas de la biosfera un espacio para la integracion de conservacion y desarollo: experiencias exitosas en Iberoamerica.

Auditoria General de la Nación. (2010). Examen del Plan de Gestión Institucional de la Administración de Parques Nacionales.

Barber, C. P., Cochrane, M. A., Souza, C. M., \& Laurance, W. F. (2014). Roads, deforestation, and the mitigating effect of protected areas in the Amazon. Biological Conservation, 177, 203-209. https://doi. org/10.1016/j.biocon.2014.07.004

Barembaum, M., \& Anastasio, M. (2005). Caracterización económica de la provincia de Santiago del Estero: evolución de la agricultura en la provincia. Apuntes Agroeconómicos, 4(3).

Bendini, M., Steimbreger, N., \& Preda, G. (2015). ¿Aceptación o resistencia campesina? respuestas a la expansión del capital en tierras extra-pampeanas. Alternativa. Revista de Estudios Rurales, 2(4).

Boisier, S. (2014). Origen, evolución y situación actual de las políticas territoriales en América Latina en los siglos XX y XXI. Planificación, prospectiva y gestión pública, reflexiones para la agenda de desarrollo. Santiago de Chile: sn.

Brown, A. D., Malizia, L. R., \& Lomáscolo, T. (2007). Reserva de la Biosfera de las Yungas: armando el rompecabezas entre todos, Argentina. Reservas de la Biosfera, 19. Recuperado de http://www.mapama. gob.es/es/parques-nacionales-oapn/proyectos-de-cooperacion/reservas-integracion_tcm7-357554. pdf \#page $=19$

Cardozo, C. F., \& Pérez Brignoli, H. (1984). Historia económica de América Latina, tomo I. Crítica, Barcelona.

Carlos, A. F. A. (2014). La ciudad como privación y la reapropiación de lo urbano como ejercicio de la ciudadanía. Scripta Nova: Revista Electrónica de Geografía y Ciencias Sociales, (18), 493. Recuperado de http://revistes.ub.edu/index.php/ScriptaNova/article/view/14979/18347

Collective, M. N. (2012). Los nuevos cercamientos. Theomai, Buenos Aires, [1990], (26). Recuperado de http:// revista-theomai.unq.edu.ar/NUMERO\%2026/MNC\%20-\%20Los\%20nuevos\%20cercamientos.pdf

De Angelis, M. (2012). Marx y la acumulación primitiva. El carácter continuo de los « cercamientos» capitalistas". Theomai 26. Recuperado de http://revista-theomai.unq.edu.ar/NUMERO\%2026/De\%20 Angelis\%20-\%20Marx\%20y\%20la\%20acumulaci\%C3\%B3n\%20primitiva.pdf

Desa, U. N. (2010). World urbanization prospects: the 2009 revision. Population Division of the Department of Economic and Social Affairs of the United Nations Secretariat, New York.

Dourojeanni, M. J. (2014). Ocupación humana y áreas protegidas de la Amazonia del Perú. Ecología Aplicada, 13(2), 225-232. https://doi.org/10.21704/rea.v13il-2.473

Galafassi, G. (2002). Racionalidad moderna y problemática ambiental. Una interpretación a la luz de la articulación sociedad-naturaleza. Galafassi, G. y Zarrilli, A. Ambiente, sociedad y naturaleza. Entre la teoría social y la historia. Bernal, Buenos. Aires: UN Quilmes Ediciones. Recuperado de http://www. aacademica.org/000-033/3 
Galafassi, G. (2012). Renovadas versiones de un proceso histórico en marcha. La predación del territorio y la naturaleza como acumulación. Revista Theomai, 25, 1-14. Recuperado de http://www.revistatheomai.unq.edu.ar/numero25/Galafassi.pdf

Galafassi, G. (2013). Conflictos por los recursos y el territorio en Patagonia Norte. Un caso de estudio en un área entre el Parque Nacional Nahuel Huapi y la cuenca del río Ñirihuau (Argentina). Scripta Nova: revista electrónica de geografía y ciencias sociales, (17), 426. Recuperado de http://www.ub.es/ geocrit/sn/sn-426.htm

Galafassi, G. (2014). Acumulación, conflictos sociales y políticas de Estado en América Latina en las últimas décadas. Cambios y rupturas en el escenario regional. Revista Encuentros Latinoamericanos Montevideo, 8(1), 48-66. http://theomai.unq.edu.ar/GEACH/ArticYPonencias/Art_Galafassi_ (Encuentros-Latinoamericanos_UDELAR).pdf

Galafassi, G., \& Roig, D. P. (2014). Nirihuau: explotación de hidrocarburos y conflicto social en las inmediaciones de Bariloche (Patagonia, Argentina).territorios, (30), 147-170. https://doi.org/10.12804/ territ30.2014.07

Galloway, G., Kengen, S., Louman, B., Stoian, D., Mery, G., Carrera Gambeta, F., ... Trevin, M. (2016). 15 Cambios en los paradigmas del sector forestal de América Latina. Forest in the Global BalanceChanging Paradigms. IUFRO World Series. Vol. 17. Recuperado de http://repositorio.bibliotecaorton. catie.ac.cr/handle/11554/8192

García-Frapolli, E., Ayala-Orozco, B., Bonilla-Moheno, M., Espadas-Manrique, C., \& Ramos-Fernández, G. (2007). Biodiversity conservation, traditional agriculture and ecotourism: Land cover/land use change projections for a natural protected area in the northeastern Yucatan Peninsula, Mexico. Landscape and urban planning, 83(2), 137-153. http://doi.org/10.1016/j.landurbplan.2007.03.007

Gavaldá, M., \& Scandizzo, H. (2008). Nirihuau: nuevo destino petrolero en territorio mapuche. Indymedia.

Geneletti, D., \& van Duren, I. (2008). Protected area zoning for conservation and use: A combination of spatial multicriteria and multiobjective evaluation. Landscape and Urban Planning, 85(2), 97-110. http://doi.org/10.1016/j.landurbplan.2007.10.004

Giaccardi, M., \& Tagliorette, A. (2007). Efectividad del manejo de las áreas protegidas marino costeras de la Argentina. Buenos Aires: Secretaría de Ambiente y Desarrollo Sustentable de la Nación, Fundación Patagonia Natural y Fundación Vida Silvestre Argentina.

Gorenstein, S. (2015). Transformaciones territoriales contemporáneas: Desafíos del pensamiento latinoamericano.EURE (Santiago), 41(122), 5-26.http://dx.doi.org/10.4067/S0250-71612015000100001

Guerrero, E., Sguerra, S., \& Rey, C. (2007). Áreas Protegidas en América Latina: De Santa Marta 1997 a Bariloche 2007. Bogotá, Parques Nacionales Naturales de Colombia y Comité Colombiano UICN.

Guerrero, J. M., \& Peyroti, G. F. (2016). Las áreas naturales protegidas de Córdoba (Argentina): desarrollo normativo y ausencia de gestión territorial. Cuadernos Geográficos, 55(1), 33-58. Recuperado de http://revistaseug.ugr.es/index.php/cuadgeo/article/view/3191/4752

Hamilton, C. M., Martinuzzi, S., Plantinga, A. J., Radeloff, V. C., Lewis, D. J., Thogmartin, W. E., .. Pidgeon, A. M. (2013). Current and future land use around a nationwide protected area network. PLoS One, 8(1), e55737. https://doi.org/10.1371/journal.pone.0055737

Harvey, D. (2004). El« nuevo» imperialismo: acumulación por desposesión. Socialist register.

Isnard, H. (1975). Lespace du géographe. En Annales de géographie (pp. 174-187). JSTOR. https://doi. org/10.3406/geo.1975.19700

Jasso, J. M. S., \& Abellán, F. C. (2015). Turismo de naturaleza en áreas protegidas de México. Una propuesta de conservación, aprovechamiento y desarrollo local en el Nevado de Toluca. Cuadernos de Turismo, (36), 339-365. http://dx.doi.org/10.6018/turismo.36.231041

Lefebvre, H. (1974). La producción del espacio. En Papers: revista de sociología (pp. 219-229). https://doi. org/10.5565/rev/papers/v3n0.880

Leff, E. (2005). La geopolítica de la biodiversidad y el desarrollo sustentable. Revista del Observatorio Social de América Latina, 17. Recuperado de http://bibliotecavirtual.clacso.org.ar/ar/libros/reggen/ pp12.pdf

Ley 25.675/2002 de 6 de noviembre, general del ambiente. Congreso de la Nación Argentina. Boletín oficial del 27/11/2002.

Ley 26.331/2007 de 28 de noviembre, de presupuestos mínimos de protección ambiental de bosques nativos. Congreso de la Nación Argentina. Boletín oficial del 19/12/2007. 
Lopes, P. F. M., Pacheco, S., Clauzet, M., Silvano, R. A. M., \& Begossi, A. (2015). Fisheries, tourism, and marine protected areas: Conflicting or synergistic interactions? Ecosystem Services, 16, 333-340. http://doi.org/10.1016/j.ecoser.2014.12.003

Mcdonald, R. I., Forman, R. T., Kareiva, P., Neugarten, R., Salzer, D., \& Fisher, J. (2009). Urban effects, distance, and protected areas in an urbanizing world. Landscape and Urban Planning, 93(1), 63-75. http://dx.doi.org/10.1016/j.landurbplan.2009.06.002

McDonald, R. I., Kareiva, P., \& Forman, R. T. (2008). The implications of current and future urbanization for global protected areas and biodiversity conservation. Biological conservation, 141(6), 1695-1703. http://dx.doi.org/10.1016/j.biocon.2008.04.025

Miranda, J. J., Corral, L., Blackman, A., Asner, G., \& Lima, E. (2016). Effects of protected areas on forest cover change and local communities: evidence from the Peruvian Amazon. World Development, 78, 288-307. https://doi.org/10.1016/j.worlddev.2015.10.026

Morea, J. P. (2014a). El Diseño de las Áreas Protegidas y su Influencia en el Desarrollo de Actividades de Uso Público: contexto Latinoamericano y situación en Argentina. Anais Brasileiros de Estudos Turísticos, 4(3), 69-80. Recuperado de https://abet.ufjf.emnuvens.com.br/abet/article/view/2875/2203

Morea, J. P. (2014b). Situación actual de la gestión de las áreas protegidas de la Argentina: Problemáticas actuales y tendencias futuras. Revista Universitaria de Geografía, 23(1), 57-75. Recuperado de http:// www.scielo.org.ar/scielo.php?script=sci_arttext\&pid=S1852-42652014000100003

Morea, J. P. (2016a). El lugar de las áreas protegidas en el marco de la planificación territorial en la Argentina: el caso del PET. Estudios Socioterritoriales, 19, 31-45. Recuperado de http://www.scielo.org. ar/pdf/esso/v19/v19a03.pdf

Morea, J. P. (2016b). Metodologías de planificación del uso público en espacios protegidos: Antecedentes y perspectivas futuras. Papeles de Geografía, (62). http://dx.doi.org/10.6018/geografia/2016/256501

Paz, R., Lipshitz, H., Zerda, H. R., \& Tiedemann, J. L. (2015). Estructura agraria, áreas de concentración de la agricultura familiar y procesos de expansión de la frontera agropecuaria en santiago del estero, argentina. revista nera, (27), 259-279. Recuperado de http://revista.fct.unesp.br/index.php/nera/ article/view/3383/2987

Sabourin, E., Samper, M., \& Sotomayor Echenique, O. (2014). Políticas públicas y agriculturas familiares en América Latina y el Caribe: balance, desafíos y perspectivas.

Santos, M. M., \& del Álamo, J. B. (2012). El uso público en la red de parques nacionales de España una propuesta de evaluación. Organismo Autónomo Parques Nacionales.

Schmidt, M. (2012). Situación de la tierra en la provincia de Salta. Una aproximación al contexto previo al Ordenamiento Territorial de Bosques Nativos. Estudios rurales, 2(3). Recuperado de http://ppct.caicyt. gov.ar/index.php/estudios-rurales/article/view/1343

Secretaria de Ambiente y Desarrollo Sustentable. (2015). Estrategia Nacional sobre la Biodiversidad y Plan de Acción 2015-2020. Buenos Aires.

Seoane, J. (2012). Neoliberalismo y ofensiva extractivista. Theomai, 26. Recuperado de http://revistatheomai.unq.edu.ar/NUMERO $\% 2026 /$ Seoane $\% 20-\% 200 f e n s i v a \% 20$ extractivista.pdf

Theodore, N., Peck, J., \& Brenner, N. (2009). Urbanismo neoliberal: la ciudad y el imperio de los mercados. Temas sociales, 66, 1-11

Vicencio Murillo, Y. (2012). Áreas Naturales y Turismo: Una ventana abierta para el buen vivir en Bahía de Los Ángeles. Tesis de Maestro en Administración Integral del Ambientereas. Colegio de la Frontera, A.C. México.

Zarrilli, A. G. (2016). Ambiente, producción y mercado. El impacto transformador en una economía periférica, el Gran Chaco Argentino en el siglo XX. Areas. Revista Internacional de Ciencias Sociales, (35), 121-139. Recuperado de http://revistas.um.es/areas/article/view/279191/204171 